\title{
Ethics of modifying the mitochondrial genome
}

A L Bredenoord, W Dondorp, G Pennings, et al.

J Med Ethics 2011 37: 97-100 originally published online November 11, 2010 doi: 10.1136/jme.2010.037481

Updated information and services can be found at:

http://jme.bmj.com/content/37/2/97.full.html

These include:

References This article cites 24 articles, 6 of which can be accessed free at: http://jme.bmj.com/content/37/2/97.full.html\#ref-list-1

Email alerting Receive free email alerts when new articles cite this article. Sign up in the service box at the top right corner of the online article.

\section{Notes}

To request permissions go to:

http://group.bmj.com/group/rights-licensing/permissions

To order reprints go to:

http://journals.bmj.com/cgi/reprintform

To subscribe to BMJ go to:

http://journals.bmj.com/cgi/ep 


\title{
Ethics of modifying the mitochondrial genome
}

\author{
A L Bredenoord, ${ }^{1}$ W Dondorp, ${ }^{2}$ G Pennings, ${ }^{3}$ G De Wert ${ }^{2}$
}

${ }^{1}$ Department of Health, Ethics and Society, Maastricht University/Julius Center, University Medical Center, Utrecht, The Netherlands ${ }^{2}$ Department of Health, Ethics and Society, Research Institutes GROW and CAPHRI, Maastricht University, Maastricht, The Netherlands

${ }^{3}$ Ghent University, Bioethics Institute Ghent, Ghent, Belgium

Correspondence to

Dr Annelien L Bredenoord, Julius Center for Health Sciences and Primary Care, University Medical Center Utrecht, Stratenum, 6.131, P0 Box 85500, 3508 GA Utrecht, The Netherlands; a.l.bredenoord@umcutrecht.nl

Received 29 April 2010 Revised 13 September 2010 Accepted 25 September 2010 Published Online First 11 November 2010

\section{ABSTRACT}

Recent preclinical studies have shown the feasibility of specific variants of nuclear transfer to prevent mitochondrial DNA disorders. Nuclear transfer could be a valuable reproductive option for carriers of mitochondrial mutations. A clinical application of nuclear transfer, however, would entail germ-line modification, more specifically a germ-line modification of the mitochondrial genome. One of the most prominent objections against germ-line modification is the fear that it would become possible to alter 'essential characteristics' of a future person, thereby possibly violating the child's right to an open future. As only the nuclear DNA would contain the ingredients for individual characteristics, modification of the mtDNA is often considered less controversial than modification of the nuclear DNA. This paper discusses the tenability of this dichotomy. After having clarified the concept of germ-line modification, it argues that modification of the mtDNA is not substantively different from modification of the nuclear DNA in terms of its effects on the identity of the future person. Subsequently the paper assesses how this conclusion affects the moral evaluation of nuclear transfer to prevent mtDNA disorders. It concludes that the moral acceptability of germ-line modification does not depend on whether it alters the identity of the future child-all germ-line modifications do-but on whether it safeguards the child's right to an open future. If nuclear transfer to prevent mtDNA disorders becomes safe and effective, then dismissing it because it involves germ-line modification is unjustified.

As there is no curative treatment, helping carriers of mitochondrial DNA (mtDNA) mutations to have healthy genetically related children has been a central focus of attention. MtDNA disorders are usually severe disorders, caused by defects in energy production. Patients show a wide variety of symptoms but generally the most energydemanding tissues such as the central nervous system, heart and skeletal muscles, liver and kidney are affected. ${ }^{1}$ One future reproductive option to prevent the transmission of an mtDNA mutation from mother to child could be nuclear transfer (or 'mitochondrial gene replacement'). Nuclear transfer involves the transfer of the nuclear DNA of a woman carrying an mtDNA mutation into an enucleated donor oocyte. This should result in healthy offspring carrying the mtDNA of the oocyte donor and the nuclear genome of the prospective parents. Nuclear transplantation can be performed before and after in-vitro fertilisation, using the nucleus of an unfertilised oocyte, the pronuclei of the zygote or the nucleus of a blastomere of an embryo. ${ }^{2-4}$ Nuclear transfer does not entail genetic selection of an embryo or fetus; it is a type of genetic intervention or modification whereby the mtDNA (which exists outside the nucleus, in the cytoplasm) is changed or replaced with the aim of correcting the genetic cause of the disease. ${ }^{5}$

Recent studies have shown that specific variants of nuclear transfer are feasible in non-human primates and in human oocytes. In a non-human primate model, researchers in Oregon transferred the spindle-chromosomal complex of a mature oocyte to an enucleated donor oocyte, resulting in three thus far healthy macaque infants. ${ }^{6}$ In the UK, researchers used abnormally fertilised human oocytes left over after in-vitro fertilisation treatment and transferred the pronuclei of a zygote to an enucleated donor oocyte. ${ }^{7}$ As a result of these technical successes, it seems only a matter of time before a first-in-human clinical application is considered. All existing reproductive options for carriers of mtDNA mutations have their limitations. ${ }^{89}$ Nuclear transfer may therefore be a valuable additional option. As having healthy, genetically related children is for many people one of the most important desires in life, helping couples to fulfil this desire is a legitimate aim of a reproductive technique such as nuclear transfer for mtDNA disease. A clinical application, however, would entail germ-line modification, more specifically a germ-line modification of the mitochondrial genome. Germ-line modification is highly controversial, as the prohibition by international declarations, such as the Council of Europe Convention on Human Rights and Biomedicine ${ }^{10}$ gives evidence of. One of the most prominent (non-safety) objections against germline modification is the fear that it would become possible to alter 'essential characteristics' of a future person, thereby possibly violating-what Feinberg in another context coined-the child's right to an open future. ${ }^{11}$ As only the nuclear DNA would contain the ingredients for our characteristics, modification of the nuclear genome has led to more ethical controversy than modification of the mitochondrial genome. In this paper, we discuss the tenability of this dichotomy. After having clarified the concept of germ-line modification, we discuss whether modification of the mitochondrial genome has the potential to affect the identity or 'essential characteristics' of the future person, and if so, how this affects the moral evaluation. By focusing on the issue of identity, we will leave aside other potential objections against nuclear transfer to prevent mtDNA disorders, such as safety issues, the moral evaluation of 'three genetic parents' and the creation and destruction of human embryos. For a review we refer the reader to Bredenoord et al. ${ }^{5}$ 


\section{GERM-LINE MODIFICATION}

We use the term germ-line modification to refer to any biomedical intervention that modifies the genome that a person can transmit to his or her child and the child's entire lineage. ${ }^{12} 13$ Not all genetic modifications affect the germ line, but genetic modifications in the still pluripotent cells of the early embryo do. Not surprisingly, the concept is usually taken as referring to germ-line modifications of the nuclear genome, ie, the DNA present in the nucleus of each cell. After all, this comprises $99.9 \%$ of the total amount of DNA (approximately 24000 genes). However, each cell also contains a second genome, located in the mitochondria. These are tiny organelles in the cytoplasm surrounding the nucleus; they serve as the "powerhouses' of the cell. The mitochondrial genome is extremely small, containing approximately $0.1 \%$ of the total amount of DNA (37 genes). The relevant genes are all involved in the cell's energy metabolism, whereas the nuclear DNA has a much wider range of functions. Transmission is also different. Unlike the nuclear genome, the mtDNA is only transmitted maternally and in a less predictable (non-Mendelian) way. However, these differences (limited quantity, specific function, maternal and non-Mendelian transmission) do not change the fact that modifications of the mitochondrial genome in early embryonic cells can be transmitted to further generations. As this is the core of the concept of germ-line modification, there is no good reason for not also applying the concept to germ-line modifications of the mitochondrial genome.

Strictly speaking, nuclear transfer for mtDNA disorders leaves the mitochondrial genome itself intact but produces a different combination of nuclear DNA and mtDNA. Although it would therefore be more precise to talk about 'mtDNA replacement' rather than 'mtDNA modification', we nevertheless use the term 'modification' as this is the term usually deployed in the literature.

\section{DOES MODIFICATION OF THE MTDNA AFFECT THE IDENTITY OF THE FUTURE CHILD?}

One of the most prominent (non-safety) objections against germ-line modification is the fear that it would become possible to alter the presumed 'essential characteristics' of a future person, thereby possibly violating the child's right to an open future. For this reason, germ-line modification of the nuclear DNA has led to more ethical controversy than modification of the mtDNA. The argument would be that the nuclear DNA contains the ingredients for our characteristics, whereas the mtDNA does not. ${ }^{14}{ }^{15}$ In 2005, the Human Fertilisation and Embryology Authority (HFEA) granted researchers in the UK a licence to determine preclinically the feasibility of a specific type of nuclear transfer for mtDNA disorders, using the pronuclei of the zygote. The HFEA explicitly started from the premise that mtDNA is not associated with 'identity or predetermined characteristics of the individual'. ${ }^{16}$ However, the assumption that modification of the mtDNA is ethically less problematical than modification of the nuclear DNA because it would not involve the possibility of altering essential characteristics is contestable for two reasons.

First, although the dominant view in science is that only the nuclear DNA contains the ingredients for our characteristics, this is not a fully settled issue. Usually, mtDNA is not considered important for our individuality, also as thousands of people have more or less identical mitochondria. The mtDNA would only govern cellular energy production. However, different authors have questioned the scientific assumption that the mtDNA is not associated with essential characteristics. Some studies, although not uncriticised, suggest associations between the mtDNA and cognitive capabilities. ${ }^{17} 18$ Other authors have remarked that mitochondria may have a significant but unknown biological function other than energy production. ${ }^{19}$ In fact, little is known about the exact role and function of the mtDNA, ${ }^{20}$ and little is known about the significance of altering the match between nuclear and mitochondrial complements. ${ }^{21-24}$ Although perhaps hypothetical, the mtDNA may influence nuclear gene expression and this, in turn, may influence the essential characteristics of the resulting child. ${ }^{25} 26$

A second reason for criticising the assumption that modification of the mtDNA does not involve the possibility of altering essential characteristics is that none of the key terms used to make this distinction (such as 'essential characteristics' and 'identity determining characteristics') are ever precisely defined. The HFEA, for example, does not explicate how it understands 'identity or predetermined characteristics of the individual'. Although it is remarkable that key concepts are not defined, this should not come as a surprise, because what is it that separates one person from another? and what exactly constitutes our identity?

The relevant question here is whether germ-line modification leads to the birth of a different person. ${ }^{27}$ In the case of other reproductive techniques, such as preimplantation genetic diagnosis, one chooses one embryo over another for implantation. If one decides to transfer embryo A instead of embryo B, this clearly leads to the birth of a different person. In the case of germ-line modification, this is less clear. The embryo is not substituted but modified; does this affect the identity of the person who is born?

Although it is beyond the scope of this paper to create a coherent account of identity, conceptual clarity may come from Parfit. ${ }^{28} \mathrm{He}$ discerns two types of identity (or 'sameness'): qualitative identity and numerical identity. Qualitative identity means that two persons or two objects are exactly alike (Parfit uses the example of two white billiard balls). Numerical identity means that two persons or objects are one and the same. For example, Barack Obama is numerically identical to the President of the United States: they are one and the same person. Identical twins may be qualitatively identical, meaning they are exactly alike. Numerically, though, they are different: they are two different persons. In some circumstances, it is meaningful to say that a person has qualitatively changed, but not numerically. A person who has had an accident may be qualitatively changed, meaning that this person's character has changed-when he changes a lot, he becomes a different person in a qualitative sense. ${ }^{29}$ Numerically though, it is the same person-once we exist, our numerical identity is quite robust through change. ${ }^{28} 29$

Similarly, germ-line modification is likely to affect the qualitative identity of the future person, whereas his/her numerical identity will be untouched. Ossorio ${ }^{27}$ convincingly explains why germ-line modification may actually change who is born (although she does not discern these two types of identity). She uses the speculative example of germ-line modification for Lesch-Nyhan syndrome, an early-onset disease characterised by mental retardation, self-mutilation and muscular and neurological abnormalities. If one could replace the gene underlying Lesch-Nyhan syndrome in the early embryo, the person who would be born would theoretically have a normal IQ, a normal life expectancy, no muscular and neurological abnormalities et cetera. Ossorio ${ }^{27}$ concludes that this person's identity has been changed, as it will have a different life experience and a different character. We prefer to specify this conclusion by adding that this person's qualitative identity has been changed. Numerically, 
though, it remains one and the same embryo-whereas in preimplantation genetic diagnosis, there is also a numerical change as an embryo is replaced with another.

Similarly, it would be difficult to maintain that a germ-line modification of the mitochondrial genome does not affect the (qualitative) identity of the future person. Even if mtDNA only has a basic cellular function, then it is still meaningful to say that germ-line modification of the mtDNA is likely to change the (qualitative) identity of the future person. After all, a person without a mtDNA disease will have a different life experience, a different biography and perhaps also a different character. This means that the dichotomy between modification of the nuclear DNA and modification of the mtDNA is untenable from this perspective; no matter whether one modifies a (pathogenic) nuclear gene or a (pathogenic) mitochondrial gene, the identity of the future person will be changed. Therefore, modification of the mtDNA cannot be considered substantively different to modification of the nuclear DNA in terms of its effects on the identity of the future person. The following step, then, is to assess how this conclusion affects the moral evaluation of nuclear transfer to prevent mtDNA disorders.

\section{MODIFICATION OF THE MTDNA AND THE CHILD'S RIGHT TO AN OPEN FUTURE}

We have concluded that modification of the mtDNA has identity-altering potential. The moot point, then, is whether such a modification could (still) be compatible with the position that one should not violate the child's right to an open future. Although debate is possible about the interpretation of this concept, taking it as a negative anticipatory autonomy right would be the most relevant and appropriate in our discussion. This means a right to have one's future options kept open until one is capable of making one's own decisions. Habermas ${ }^{30}$ has argued that genetic modification may entail a prejudgement of specific life projects, which may imperil autonomy. It threatens the child being the author of its life, because others have already framed it, or the child could have the feeling he/she is tailored towards its parents' expectations. In other words, by choosing the genetic make-up of a child, its right to an open future is violated. As we endorse the position that in a pluralist liberal society one should allow people to be the authors of their lives, ${ }^{31}$ it would indeed be problematical when germ-line modification would restrict a child's options in life, or when it would predetermine a child towards specific life projects. It is therefore important to assess whether germ-line modification of the mtDNA may indeed potentially threaten the child's right to an open future.

Despite the fact that a germ-line modification of the mtDNA is likely to alter the identity of the child, a clinical application of nuclear transfer to prevent mtDNA could still be compatible with the position that one should not violate the child's right to an open future. To prevent a child being predetermined towards a specific plan of life, it seems reasonable only to allow modifications that broadens so-called 'general purpose means'. ${ }^{32}$ These are capacities that are useful and valuable for carrying out nearly all plans of life. In other words, we should only allow genetic modifications of which we can assume that they give children traits that are useful for all conceptions of a good life. ${ }^{31}$ Although debate is possible (and necessary) about what general purpose means exactly are, being healthy should clearly be included. Health, after all, is a sine qua non for many (although not all) plans of life. Disabilities and disorders often (although not always) mean that people have less good lives than they would have had. ${ }^{33}$ It is reasonable to assume that a child with a serious neurological or muscular disorder will experience the disease (and the underlying mtDNA mutation) as a barrier for many life plans. This is not to say that these children cannot have satisfactory lives, but if germ-line modification can safely avoid the sometimes devastating effects of the mtDNA mutation, it is reasonable to presume that the future child will have more options in life. Also Habermas ${ }^{30}$ would probably allow this application, as he allows germ-line modification 'for the goal of avoiding evils that are unquestionably extreme and likely to be rejected by all'.

To conclude, the mtDNA modification is likely to alter the identity of the child, but it does not necessarily limit the child's future options. On the contrary, the child may even have more options in life. Whether the child's improved health compensates for the drastic intervention is an assessment that can only be made case by case, depending on the likelihood of developing disease symptoms, the expected seriousness of the disease and the expected 'costs' in the trade-off (including the risks of the intervention).

As we concluded earlier that modification of the mtDNA is not substantively different from modification of the nuclear DNA in terms of its effects on the identity of the future person, any conclusion regarding the moral acceptability of modifying the mtDNA applies mutatis mutandis to modification of the nuclear genome. This means that modification of the nuclear genome is equally acceptable as long as, other things being equal, this does not violate the child's right to an open future. Moreover, it would be interesting to explore whether and to what extent the concept of general purpose means is useful in judging the acceptability of germ-line modification intended to enhance human traits. Clearly, the right to an open future would only serve as a necessary but not sufficient criterion for assessing the ethics of enhancement, as other relevant factors, such as safety and justice issues, need to be taken into account as well. It would also require further filling in which enhancements would potentially count as future widening and which as future narrowing. ${ }^{34}$

\section{CONCLUSION}

Germ-line modification of the mtDNA is often considered less controversial than modification of the nuclear DNA, as the presumption is that it is the nuclear DNA that contains the ingredients for our characteristics. Modification of the mtDNA would not affect the identity of the future child, thereby not carrying the possibility of violating the child's right to an open future. In this paper we have argued that even if the mtDNA only has a basic cellular function then it is still meaningful to say that a germ-line modification of the mtDNA is likely to change the (qualitative) identity of the future person. This means that the dichotomy between modification of the nuclear DNA and modification of the mtDNA is untenable from this perspective; no matter whether one modifies the nuclear genome or the mitochondrial genome, the identity of the future child will be changed. This is not to say that the distinction may not be relevant from other perspectives. Modification of the nuclear DNA may for example be riskier, as it requires a disruption of the nuclear membrane. ${ }^{14}$

We have argued that the moral acceptability of germ-line modification does not depend on whether it alters the identity of the future child-all germ-line modifications do-but on whether it safeguards the child's right to an open future. To prevent that a child is predetermined towards a specific plan of life, we should only allow germ-line modification (of both the nuclear and mtDNA) that broadens so-called 'general purpose 
means', which are capacities that are useful and valuable for carrying out nearly all plans of life. As health is a sine qua non for many plans in life, modification of the mtDNA would establish a more open future. It would therefore be an acceptable application of germ-line modification. Of course, the overall acceptability of using nuclear transfer for this purpose would also depend on other relevant moral factors, such as the (intergenerational) safety and efficacy of the procedure. As mitochondria are transferred maternally, men will not pass on any mutant mtDNA to their offspring. This may be a reason to consider only creating male embryos, at least in the initial applications. ${ }^{35}$ In addition, a further reflection on the role and position of the oocyte donor is necessary. Nuclear transfer for mtDNA disorders results in a child carrying the nuclear genome of its parents and the mitochondrial genome from the oocyte donor. This invokes still unaddressed conceptual and ethical questions regarding the interpretation of (genetic) parenthood. Although there is an array of ethical questions associated with nuclear transfer to prevent mtDNA disorders that urgently needs ethical debate, the fact that nuclear transfer with the aim of preventing the transmission of mtDNA disease would involve germ-line modification cannot convincingly be construed as a categorical moral objection against the possible use of this technology.

Funding This work was supported by a grant from the Ter Meulen Fund, Royal Netherlands Academy of Arts and Sciences, The Netherlands and by GROW, School for Oncology and Developmental Biology, Maastricht University.

Competing interests None.

Provenance and peer review Not commissioned; externally peer reviewed.

\section{REFERENCES}

1. Taylor RW, Turnbull DM. Mitochondrial DNA mutations in human disease. Nat Rev Genet 2005;6:389-402.

2. De Wert G. Human cloning: the case of the (preimplantation) embryo, and ethical exploration. In: Gunning J, ed. Assisted conception. Research ethics and law. Aldershot: Ashgate Darthmouth, 2000:83-107.

3. Brown DT, Herbert M, Lamb VK, et al. Transmission of mitochondrial DNA disorders: possibilities for the future. Lancet 2006;368:87-9.

4. Roberts RM. Prevention of human mitochondrial (mtDNA) disease by nucleus transplantation into an enucleated donor oocyte. Am J Med Genet 1999;87:265-6.

5. Bredenoord AL, Pennings G, de Wert G. Ooplasmic transfer and nuclear transfer to prevent mitochondrial DNA disorders: conceptual and normative issues. Hum Reprod Update 2008;14:669-78.

6. Tachibana M, Sparman M, Sritanaudomchai H, et al. Mitochondrial gene replacement in primate offspring and embryonic stem cells. Nature 2009:461:367-72

7. Craven L, Tuppen HA, Greggains GD, et al. Pronuclear transfer in human embryos to prevent transmission of mitochondrial DNA disease. Nature 2010;465:82-5

8. Bredenoord AL, Pennings G, Smeets HJ, et al. Dealing with uncertainties. Ethics of prenatal diagnosis and preimplantation genetic diagnosis to prevent mitochondrial disorders. Hum Reprod Update 2008;14:83-94.

9. Bredenoord AL, Dondorp W, Pennings G, et al. PGD to reduce reproductive risk: the case of mitochondrial DNA disorders. Hum Reprod 2008;23:2392-401.
10. Council of Europe. Convention for Protection of Human Rights and Dignity of the Human Being with Regard to the Application of Biology and Biomedicine: Convention of Human Rights and Biomedicine. Kennedy Institute Ethics Journal 1997;7:277-90.

11. Feinberg J. The child's right to an open future. In: Aiken W, LaFolette H, eds. Whose child? Children's rights, parental authority, and state power. Totowa NJ: Rowman and Littlefield, 1980.

12. Chapman AR, Frankel MS, eds. Designing Our Descendants. The Promise and Perils of Genetic Modification. Baltimore and London: The Johns Hopkins University Press, 2003.

13. Baruch S, Huang A, Pritchard D, et al. Human Germline Genetic Modification: Issues and Options for Policymakers. Washington, DC: Genetics and Public Policy Center, 2005.

14. Rubenstein DS, Thomasma DC, Schon EA, et al. Germ-line therapy to cure mitochondrial disease: protocol and ethics of in vitro ovum nuclear transplantation. Cambr 0 Healthc Ethics 1995;4:316-39.

15. Sato A, Kono T, Nakada K, et al. Gene therapy for progeny of mito-mice carrying pathogenic mtDNA by nuclear transplantation. Proc Natl Acad Sci U S A 2005; 102:16765-70.

16. Human Fertilization and Embryology Authority R0153. http://www.hfea.gov.uk./docs/ R0153 How the decision was made to licence this research project 2 .pdf (accessed 25 Oct 2010)

17. Roubertoux PL, Sluyter F, Carlier M, et al. Mitochondrial DNA modifies cognition in interaction with the nuclear genome and age in mice. Nat Genet 2003;35:65-9.

18. Moreno-Loshuertos R, Acin-Perez R, Fernandez-Silva P, et al. Differences in reactive oxygen species production explain the phenotypes associated with common mouse mitochondrial DNA variants. Nat Genet 2006;38:1261-8.

19. Nagao Y, Totsuka Y, Atomi Y, et al. Decreased physical performance of congenic mice with mismatch between the nuclear and the mitochondrial genome. Genes Genet Syst 1997;73:21-7

20. Thorburn DR, Dahl HH, Singh KK. The pros and cons of mitochondrial manipulation in the human germ line. Mitochondrion 2001;1:123-7.

21. Bonnicksen AL. The politics of germline therapy. Nat Genet 1998;19:10-11.

22. Bowles EJ, Campbell KH, St John JC. Nuclear transfer: preservation of a nuclear genome at the expense of its associated mtDNA genome(s). Curr Top Dev Biol 2007;71:268-84.

23. St John JC, Lloyd REl, Bowles EJ, et al. The consequences of nuclear transfer for mammalian foetal development and offspring survival. A mitochondrial DNA perspective. Reproduction 2004;127:631-41.

24. Poulton J, Kennedy S, Oakeshott $\mathrm{P}$, et al. Nuclear transfer to prevent mitochondrial DNA diseases. Lancet 2006;368:841.

25. Szebik I. Altering the mitochondrial genome: is it just a technical issue? Response to 'germ line therapy to cure mitochondrial disease: protocol and ethics of in vitro ovum nuclear transplantation'. Cambr 0 Healthc Ethics 1999;8:369-74.

26. Parens E, Juengst E. Inadvertently crossing the germ line. Science 2001;292:397.

27. Ossorio PN. Inheritable genetic modifications: do we owe them to our children? In: Chapman AR, Frankel MS, eds. Designing our descendants. The promise and perils of genetic modification. Baltimore and London: Johns Hopkins University Press, 2003:252-71.

28. Parfit D. Reasons and Persons. Oxford: Oxford University Press, 1984.

29. DeGrazia D. Human Identity and Bioethics. Cambridge: Cambridge University Press, 2005.

30. Habermas J. The Future of Human Nature. Cambridge: Polity Press, 2003.

31. Dekker TJ. The illiberality of perfectionist enhancement. Med Health Care Philos 2009;12:91-8.

32. Buchanan A, Brock DW, Daniels N, et al. From Chance to Choice. Genetics and Justice. Cambridge: Cambridge University Press, 2000.

33. Glover J. Choosing Children. Genes, Disability, and Design. Oxford: Clarendon Press, 2006.

34. Bredenoord AL, Van der Graaf R, Van Delden JJM. Towards a "post-posthuman dignity area" in evaluating emerging enhancement technologies. Am J Bioeth 2010:10:55-7.

35. Bredenoord AL, Dondorp WJ, Pennings G, et al. Avoiding transgenerational health risks of mitochondrial DNA disorders: a morally acceptable reason for sex selection? Human Reprod 2010;25:1354-60. 